\title{
ACKA 500 WATT POWER AMPLIFIER FOR A 144 MHZ CHANNEL BASED ON A VHF PUSH-PULL POWER MOS TRANSISTOR
}

\author{
Agus Harjoko and Tri Wahyu Supardi \\ Department of Computer Science and Electronics, FMIPA, Gadjah Mada University, Indonesia
}

Received 2013-07-03, Revised 2013-08-06; Accepted 2013-08-26

\begin{abstract}
In a wireless communication, a signal power amplifier is needed to carry signals over a long distance. Many signal amplifiers are made of tube as the amplifying component and as such they suffer low efficiency. This study presents results of the research on designing and implementing solid state $144 \mathrm{MHz}$ signal amplifier employing MOSFET BLF278 as the active component of the amplifier. The amplifier has an automatic activation switch, an input terminal, a $50 \mathrm{ohm}$ impedance output terminal and a bypass system for two way communication. This amplifier has been tested on frequencies between $144.00 \mathrm{MHz}$ to $146.90 \mathrm{MHz}$ in 100 $\mathrm{KHz}$ steps without adjusting the tuning. It is found that the signal amplifier delivers RF powers up to 500 watt at the working voltage of 48 volt with the efficiency of $77 \%$. The amplifier has a Standing Wave Ratio (SWR) of 1:1 when amplifying and 1.1:1.0 when in bypass mode. The signal amplifier has been tested successfully for radio communication between Sukoharjo in Central Jawa and Surabaya in East Jawa.
\end{abstract}

Keywords: Push-Pull, RF Power Amplifier, Solid State

\section{INTRODUCTION}

In a wireless communication, a signal amplifier is required in order to deliver signal over a long distance (Cripps, 2006; Harjoko and Supardi, 2009). One such amplifier is a Radio Frequency (RF) amplifier which amplifies the power of a signal carrier. Most amplifiers used to generate a high-power RF signal are based on electron tube as the amplifying component. Unfortunately, such amplifiers suffer from a low efficiency compared to solid state amplifiers (Cripps, 2002; 2006). Such amplifiers also require a high voltage to operate and need tuning in their operations. Thus, such amplifier is not suitable for digital communication and for system with limited energy and for system requiring flexible activation. On the other hand, solid state amplifier has limited power amplification due to the energy limitation of the transistor.

Early design on RF power amplifier was reported by (Doherty, 1936) where plate circuit efficiency of sixty to sixty five percent was obtained. Idealized operation of a Corresponding Author: Agus Harjoko, Department of Computer Science and Electronics, FMIPA, Gadjah Mada University, Indonesia power amplifier and insight into the operation of VHFUHF power amplifier was analyzed in (Raab, 1977). The availability of Field Effect Transistor (FET) device has inspired researchers to overcome the limitation of the electron tube and transistor based signal amplifier and to design and fabricate more efficient FET-based power amplifier (Radisic et al., 1998). More specialized RF power amplifiers for wireless communication technologies have been developed, such as for CDMA application (Hanington et al., 1999), for WCDMA application (Joshin et al., 2003), for EDGE-GSM application (Reynaert and Steyaert, 2005), for 802.11g WLAN application (Wang et al., 2006) and for OFDM (Wang et al., 2007). A comparative overview of microwave and wireless power-amplifier behavioral modeling approaches was reported by (Pedro and Mass, 2005), whereas (Jeong et al., 2007) developed MOPA. A 300 watt MOSFET based power amplifier was billed by Horlin (2007).

MOSFET technology has inspired the authors to design and implement a MOSFET based signal amplifier. One of the MOSFET available today is the BLF278 
made by (Phillips, 1996). This MOSFET is used in broadcast frequency of $108 \mathrm{MHz}$ and $225 \mathrm{MHz}$ bands. In this research, $144 \mathrm{MHz}$ RF signal amplifier based on MOSFET BLF278 is designed, implemented and tested.

The amplifier is designed to deliver up to 500 watt power due to the long distance communication requirement.

\section{POWER AMPLIFIER DESIGN}

The RF power amplifier is designed to be integrated with the existing RF communication system. Figure 1 shows how the RF power amplifier fit into a radio communication system.

In Fig. 1, when the amplifier is in a transmission mode, the RF power amplifier amplifies signal from transceiver. In a receiving mode, the amplifier is not active or be bypassed automatically. However, the impedance on either mode has to remain matching with the antenna system, which is $50 \mathrm{ohm}$. For this reason, input and output matching networks are added to the system as shown in Fig. 2. For operational flexibility, the amplifier must be able to be activated automatically whenever needed.

The amplifier is intended to work on a two way communication system on a 2-meter band or 144.00 MHz. In addition, a high amplification factor is required such that small input signal is sufficient. In a two way communication system, the system has to have two modes, active mode (transmitter mode) and standby mode (bypass mode), as required by the Interconnection Control System (ICS). Since the amplifier is to be employed in a two way communication, it is designed to operate in two modes, the transmitter mode and receiver mode. When the amplifier is in a transmission mode or active mode, the RF power amplifier amplifies signal from transceiver. In a receiving mode or bypass mode, the amplifier is not active or be bypassed automatically. Thus, control circuit is added to activate or deactivate the power amplifier. The matching circuit is implemented to match the impedance of the amplifier system with the antenna system. The overall design of the RF amplifier that meet the requirement is shown in Fig. 3 .

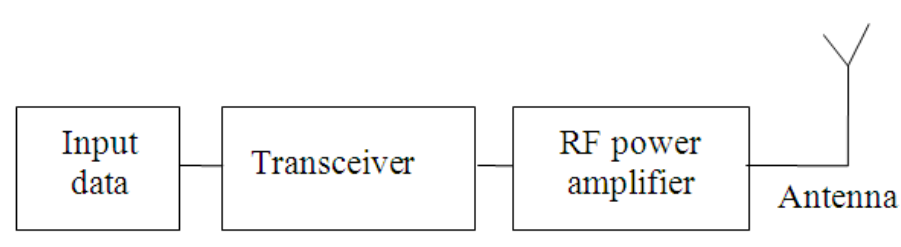

Fig. 1. RF Power amplifier in a radio communication system

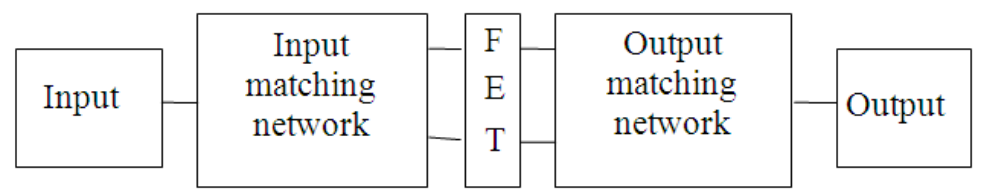

Fig. 2. Impedance matching network of the RF amplifier

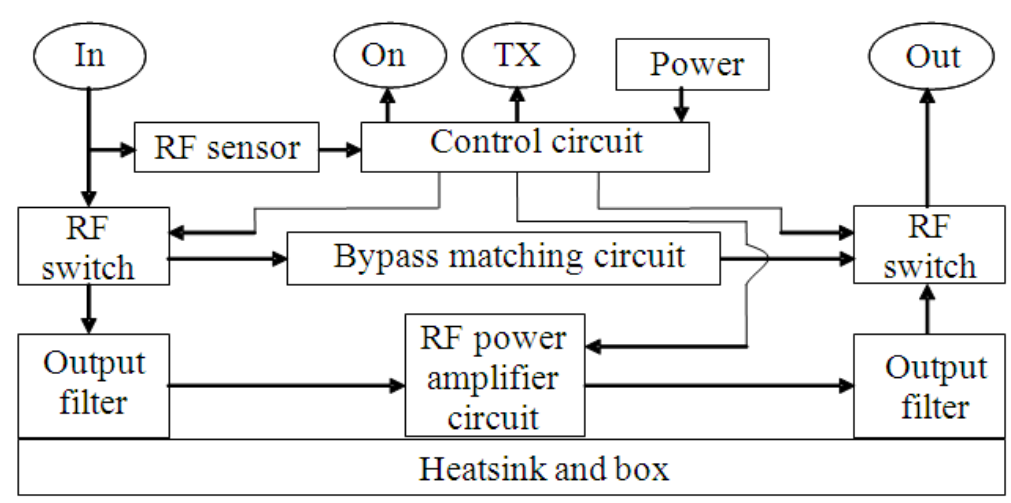

Fig. 3. Block diagram of the RF power amplifier system 


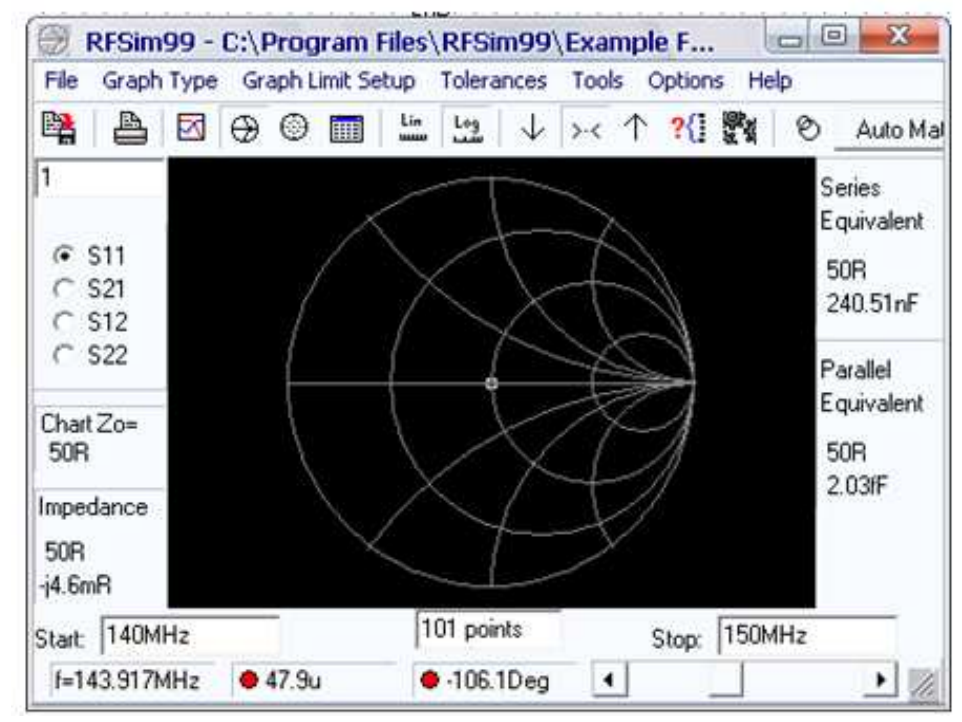

Fig. 4. Smith diagram of the amplifier design

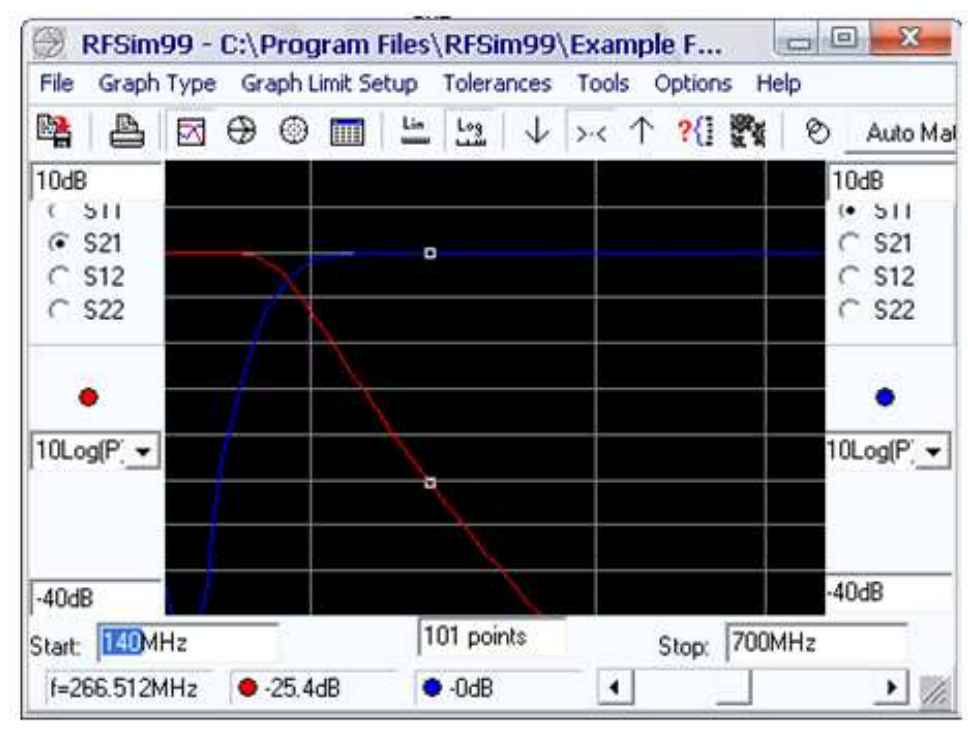

Fig. 5. Simulation output of the filter design

Based on the above requirement, MOSFET BLF278 from Phillips is selected as the active component in a push-pull configuration. MOSFET BLF278 is a solid state component which is expected to give a high efficiency. MOSFET BLF278 is commonly used in a one way communication, such as radio broadcast, delivering 300 watt output for $108 \mathrm{MHz}$ band and operates continuously. In that application, the input is normally around 3 watts. Since, in the two-way communication system the system does not have to transmit signal continuousy, thus the amplifier can be operated to deliver a much higher output for a short period of time. The simulation result is shown in Fig. 4.

In a high-power communication system, it is important to add filters to the amplifier in order to prevent the harmonic signal from disturbing the harmonic frequency of the band and for safety reason. The simulation of the filter response is shown in Fig. 5. 
The cooling system is designed to be based on air flow. In order to provide the required cooling, the material was made of copper aluminum heatsink. The copper distribute heat from the active component whereas the aluminum quickly releases heat into the air through the heatsink's fin. The heatsink functionality is enhanced by its large mass as the heatsink is designed in layers and as the cover box of the amplifier. This way, the heatsink provides Electromagnetic Interference (EMI) shielding functionality, protecting the amplifier from RF radiation. The implementation of the designed heatsink is shown in Fig. 6.

\section{POWER AMPLIFIER TESTING RESULTS}

The RF power amplifier is packed in a black box made of aluminum as shown in Fig. 6. As discussed previously the box also functions as heatsink.

\subsection{Laboratory Test}

The RF power amplifier is tested to obtain its performance. Parameters tested include input Standing Wave Ratio (SWR) values for both trasmitter and receiver modes, output RF power and overall input current. The system diagram during the testing is shown in Fig. 7.
The laboratory test results are shown in the following tables. Table 1 shows the SWR values of the RF amplifier both in receiver mode and transmitter mode (denoted "bypass mode" and "active mode" respectively in the table). The frequency was varied from $144 \mathrm{MHz}$ to $146.9 \mathrm{MHz}$ in $100 \mathrm{KHz}$ steps and the SWR was measured.

Table 2 shows the performance of the RF power amplifier. The second column shows the RF power output. The third and fourth columns show the input current and voltage applied to the amplifier. The fifth column shows the input power, calculated as current multiplied by voltage. The sixth column shows the efficiency of the RF power amplifier. The RF power amplifier was tested to deliver output from 100 watt up to 500 watt.

\subsection{Field Test}

Having successfully completed the laboratory test, a field test is conducted. For the field test, the input is given by KENWOOD TR-9130. The antenna is erected $40 \mathrm{~m}$ high above the ground. One tranceiver system is located in Parangjoro village, district of Sukoharjo, the province of Central Java, Indonesia. The other transceiver system is located in Surabaya, province of East Java which is $300 \mathrm{~km}$ away. A Kenwood TR-9130 transceiver is used in this experiment.

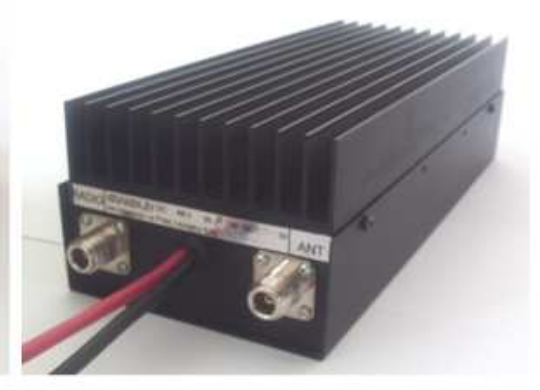

Fig. 6. The RF power amplifier box and heatsink (front and rear view)

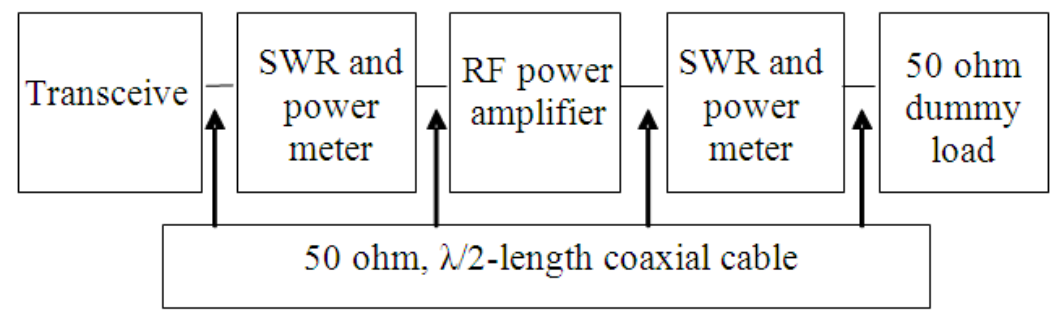

Fig. 7. The testing diagram 
Table 1. SWR values at the input terminal

\begin{tabular}{llll}
\hline No & $\begin{array}{l}\text { Frrequency } \\
(\mathrm{MHz})\end{array}$ & $\begin{array}{l}\text { SWR } \\
\text { (bypass mode) }\end{array}$ & $\begin{array}{l}\text { SWR } \\
\text { (active mode) }\end{array}$ \\
\hline 1 & 144.00 & $1.1: 1$ & $1.0: 1$ \\
2 & 144.10 & $1.1: 1$ & $1.0: 1$ \\
3 & 144.20 & $1.1: 1$ & $1.0: 1$ \\
4 & 144.30 & $1.1: 1$ & $1.0: 1$ \\
5 & 144.40 & $1.1: 1$ & $1.0: 1$ \\
6 & 144.50 & $1.1: 1$ & $1.0: 1$ \\
7 & 144.60 & $1.1: 1$ & $1.0: 1$ \\
8 & 144.70 & $1.1: 1$ & $1.0: 1$ \\
9 & 144.80 & $1.1: 1$ & $1.0: 1$ \\
10 & 144.90 & $1.1: 1$ & $1.0: 1$ \\
11 & 145.00 & $1.1: 1$ & $1.0: 1$ \\
12 & 145.10 & $1.1: 1$ & $1.0: 1$ \\
13 & 145.20 & $1.1: 1$ & $1.0: 1$ \\
14 & 145.30 & $1.1: 1$ & $1.0: 1$ \\
15 & 145.40 & $1.1: 1$ & $1.0: 1$ \\
16 & 145.50 & $1.1: 1$ & $1.0: 1$ \\
17 & 145.60 & $1.1: 1$ & $1.0: 1$ \\
18 & 145.70 & $1.1: 1$ & $1.0: 1$ \\
19 & 145.80 & $1.1: 1$ & $1.0: 1$ \\
20 & 145.90 & $1.1: 1$ & $1.0: 1$ \\
21 & 146.00 & $1.1: 1$ & $1.0: 1$ \\
22 & 146.10 & $1.1: 1$ & $1.0: 1$ \\
23 & 146.20 & $1.1: 1$ & $1.0: 1$ \\
24 & 146.30 & $1.1: 1$ & $1.0: 1$ \\
25 & 146.40 & $1.1: 1$ & $1.0: 1$ \\
26 & 146.50 & $1.1: 1$ & $1.0: 1$ \\
27 & 146.60 & $1.1: 1$ & $1.0: 1$ \\
28 & 146.70 & $1.1: 1$ & $1.0: 1$ \\
29 & 146.80 & $1.1: 1$ & $1.0: 1$ \\
30 & 146.90 & $1.1: 1$ & $1.0: 1$ \\
\hline & & &
\end{tabular}

Table 2. RF power output and the amplifier efficiency

\begin{tabular}{llllll}
\hline & $\begin{array}{l}\text { RF } \\
\text { Output } \\
\text { (watt) }\end{array}$ & $\begin{array}{l}\text { Current } \\
\text { voltage } \\
\text { (ampere) }\end{array}$ & $\begin{array}{l}\text { DC } \\
\text { voltage } \\
\text { (volt) }\end{array}$ & $\begin{array}{l}\text { DC input } \\
\text { power } \\
\text { (watt) }\end{array}$ & $\begin{array}{l}\text { Efficiency } \\
(\%)\end{array}$ \\
\hline 1 & 100 & 5.0 & 47.9 & 239.50 & 42 \\
2 & 150 & 6.3 & 47.9 & 301.77 & 50 \\
3 & 200 & 7.6 & 47.8 & 363.28 & 55 \\
4 & 250 & 8.6 & 47.7 & 410.22 & 61 \\
5 & 300 & 9.6 & 47.6 & 456.96 & 66 \\
6 & 350 & 10.6 & 47.5 & 503.50 & 70 \\
7 & 400 & 11.6 & 47.4 & 549.84 & 73 \\
8 & 450 & 12.6 & 47.3 & 595.98 & 76 \\
9 & 500 & 13.8 & 47.2 & 651.36 & 77 \\
\hline
\end{tabular}

\section{DISCUSSION}

The experimental results shown in Table 1 and $\mathbf{2}$ show that the impedance of the RF amplifier matches the overall communication system. The amplifier has SWR 1:1 in the transmitter mode and SWR 1.1:1.0 in the receiver or bypass mode. It is observed that the power loss at the bypass mode is one watt $(3.3 \%)$ when operating at 30 watt input.

Table 2 shows that the RF power amplifier could deliver output from 100 watt up to 500 watt. The efficiency ranges from $42 \%$ up to $77 \%$. The efficiency increases as the output power increases. The highest efficiency occurs at the output power 500 watt. This efficiency is higher compared to Joshin et al. (2003) and Wang et al. (2007) and comparable to Jeong et al. (2007). Table 1 and 2 show that MOSFET BLF278 can be used in a $144 \mathrm{MHz}$ RF power amplifier.

Field test shows that the power amplifier could deliver signal as far as $300 \mathrm{~km}$. On that experiment, communication was successful and the power amplification was consistent with the laboratory test.

\section{CONCLUSION}

A solid state $144 \mathrm{MHz}$ RF power amplifier has been designed and implemented using MOSFET BLF278 as the active signal amplifier giving output up to 500 watt at the working voltage of 48 volt.

The RF amplifier has been tested on a two way communication system with SWR value 1:1 when operating at the active mode and SWR value 1.1:1.0 when operated at the bypass mode. The distance between the transmitter and the receiver was $300 \mathrm{~km}$.

The RF amplifier can be used to replace the tube-based amplifier. This solid state amplifier gives better efficiency (77\%, at the RF output of 500 watt), better safety (working voltage is 48 volt) and easier operation at $144.00-146.90 \mathrm{MHz}$ (without tuning).

\section{ACKNOWLEDGEMENT}

This research was partly funded by a research grant from the Electronic and Instrumentation study program, FMIPA, Gadjah Mada University, Indonesia.

\section{REFERENCES}

Cripps, S.C., 2002. Advanced Techniques in RF Power Amplifier Design. 1st Edn., Artech House, Boston, ISBN-10: 158053564X, pp: 320.

Cripps, S.C., 2006. RF Power Amplifiers for Wireless Communications. 2nd Edn., Artech House, Incorporated, Boston, ISBN-10: 1596930187, pp: 456.

Doherty, W.H., 1936. A new high efficiency power amplifier for modulated waves. Proceedings Institute of RFIC Virtual Journal, Radio Engineers, (RE' 63), IEEE Xplore Press, pp: 1163-1182. DOI: 10.1109/JRPROC.1936.228468 
Hanington, G., P.F. Chen, P.M. Asbeck, L.E. Larson, 1999. High-efficiency power amplifier using dynamic power-supply voltage for CDMA applications. IEEE Trans. Microwave Theory Techn., 47: 14711476. DOI: $10.1109 / 22.780397$

Harjoko, A. and W.T. Supardi, 2009. Design of a multifunction module with wired and wireless communication capability. Proceedings International Conference on Science and Technology, Jan. 24-24, YOGYAKARTA, Indonesia, pp: 1090-1092.

Horlin, G., 2007. Design and building of a 300 W MOSFET push-pull power amplifier for $144 \mathrm{MHz}$.

Jeong, Y., J. Nilsson, J.K. Sahu, D.N. Payne and R. Horley et al., 2007. Power scaling of singlefrequency ytterbium-doped fiber master-oscillator power-amplifier sources up to $500 \mathrm{~W}$. IEEE J. Selected Topics Quantum Electron., 13: 546-551. DOI: 10.1109/JSTQE.2007.896639

Joshin, K., T. Kikkawa, H. Hayashi, T. Maniwa and S. Yokokawa et al., 2003. A $174 \mathrm{~W}$ high-efficiency GaN HEMT power amplifier for W-CDMA base station applications. Proceedings of the IEEE International Electron Devices Meeting, Dec, 8-10, IEEE Xplore Press, Washington, DC, USA. DOI: 10.1109/IEDM.2003.1269444

Pedro, J.C. and S.A. Maas, 2005. A comparative overview of microwave and wireless power-amplifier behavioral modeling approaches. IEEE Trans. Microwave Theory Techn., 53: 1150-1163. DOI: 10.1109/TMTT.2005.845723
Phillips, 1996. BLF278 VHF Push-Pull Power MOS Transistor.

Raab, F.H., 1977. Idealized operation of the class E tuned power amplifier. IEEE Trans. Circ. Syst., 24: 725-735. DOI: 10.1109/TCS.1977.1084296

Radisic, V., Y. Qian and T. Itoh, 1988. Broadband power amplifier using dielectric photonic bandgap structure. IEEE Microwave Guided Wave Lett., 8: 13-14. DOI: 10.1109/75.650973

Reynaert, P. and M.S.J. Steyaert, 2005. A $1.75-\mathrm{GHz}$ polar modulated CMOS RF power amplifier for GSM-EDGE. IEEE J. Solid-State Circ., 40: 25982608. DOI: $10.1109 /$ JSSC.2005.857425

Wang, F., D.F. Kimball, D.Y. Lie, P.M. Asbeck, L.E. Larson, 2007. A monolithic high-efficiency 2.4$\mathrm{GHz}$ 20-dBm SiGe BiCMOS envelope-tracking OFDM power amplifier. IEEE J. Solid-State Circ., 42: 1271-1281. DOI: 10.1109/JSSC.2007.897170

Wang, F., D.F. Kimball, J.D. Popp, A.H. Yang and D.Y. Lie et al., 2006. An improved power-added efficiency $19-\mathrm{dBm}$ hybrid envelope elimination and restoration power amplifier for 802.11g WLAN Applications. IEEE Trans. Microwave Theory Techn., 54: 4086-4099. DOI: 10.1109/TMTT.2006.885575. 